\title{
Intraoperative Hypotension and Related Risk Factors for Postoperative Mortality After Noncardiac Surgery in Elderly Patients: A Retrospective Analysis Report
}

Benhui Zhao, ${ }^{\text {, } * \text { Xingtong }}$

Chen, (D) ${ }^{1} *$ Qian Chen, ${ }^{1,2}$ Gaoming $\mathrm{Li}^{3}{ }^{3}$ Zhe Chen, ${ }^{4}$ Ziheng Yang,' Li Gu,' Xudong Xiao, ${ }^{5}$ Zhen Wang, ${ }^{6}$ Jiaolin Ning,' Bin Yi,' Kaizhi Lu, 'Hongyan Zhang, ${ }^{7}$ Jianteng Gu (D) ${ }^{\prime}$

'Department of Anesthesiology, Southwest Hospital, Third Military Medical University (Army Medical University), Chongqing, People's Republic of China; ${ }^{2}$ Anaesthetics, Pain Medicine and Intensive Care, Department of Surgery and Cancer, Faculty of Medicine, Imperial College London, Chelsea \& Westminster Hospital, London, UK; ${ }^{3}$ Department of Health Statistics, Third Military Medical University (Army Medical University), Chongqing, People's Republic of China; ${ }^{4}$ Quality Management and Control Department, Southwest Hospital, Third Military Medical University (Army Medical University), Chongqing, People's Republic of China; ${ }^{5}$ Department of Anesthesiology, Xinqiao Hospital, Third Military Medical University (Army Medical University), Chongqing, People's Republic of China; ${ }^{6}$ Department of Anesthesiology, ${ }^{7}$ Hospital Office, Daping Hospital, Third Military Medical University (Army Medical University), Chongqing, People's Republic of China

*These authors contributed equally to this work

Correspondence: Jianteng Gu; Hongyan Zhang

Email jiantenggu@hotmail.com; etengyan@I63.com
Background: Blood pressure fluctuation is very common during non-cardiac surgery in elderly. This retrospective study was to analyse whether intraoperative hypotension in elderly and other risk factors relate to the postoperative mortality.

Methods: A total of 118 cases (Observational group), who underwent noncardiac surgery in three medical centers between September 2014 and March 2017, and died in the hospital after the noncardiac surgery. With 1:2 ratio of propensity matching, 236 survival cases (Control group) were selected for comparison analyses with the death cases. Intraoperative blood pressure and perioperative parameters from both groups were collected from electronic anaesthesia charts. Data were analysed with univariate logistic regression analysis where variables with $p$ values less than 0.05 were analysed with multivariate logistic regression analysis. The receiver operating characteristic (ROC) curve was constructed.

Results: There are five risk factors related to postoperative death in elderly patients: ASA grade, COPD, emergency surgery, general anesthesia, $60<\mathrm{MAP} \leq 65 \mathrm{mmHg}(\mathrm{OR}>1)$, and one factor may reduce the risk of postoperative mortality, which is PACU therapy $(\mathrm{OR}<1)$. Compared with the Control group, the Observational group had a higher proportion of cerebral hernia, kidney injury and trauma $(p<0.001)$. The intraoperative blood transfusion volume and intraoperative blood loss volume were higher in the Observational group than the Control group $(p<0.001)$. The proportion of using vasoactive drugs was higher in the Observational group $(p<0.001)$, and there was more urine output during the operation in the Observational group ( $p=0.005)$.

Conclusion: The intraoperative MAP of geriatric patients lower than $65 \mathrm{mmHg}$ is highly related to the postoperative mortality. Elderly patients with emergency surgery, high ASA grade and a history of COPD have an increased risk of postoperative mortality. General anesthesia is a risk factor for postoperative death in elderly patients, and the PACU therapy is a protective factor to avoid postoperative death.

Trial Registration: This study has been retrospectively registered in the Chinese Clinical Trials Registry (ChiCTR2000038912, 10/10/2020).

Keywords: intraoperative hypotension, geriatric patients, COPD, postoperative mortality, non-cardiac surgery

\section{Introduction}

With the acceleration of the social aging process and the increase of the elderly population, the proportion of elderly patients undergoing surgical treatment also increased gradually. ${ }^{1}$ Due to the organs functional degradation in elderly patients, most of them 
often suffer from various complications in the perioperative period, and the postoperative mortality rate is 4.4 times that of middle-aged and young patients. ${ }^{2}$ Therefore, the risk factors associated with postoperative mortality in elderly patients are worth carefully analyzing.

Geriatric patients with decreased vascular selfregulation ability are prone to blood pressure fluctuations and hypotension. Besides, vital organs become more vulnerable for they are less able to tolerate hypotension. ${ }^{3}$ Many risk factors bring great challenges to the management of intraoperative anesthesia. Maintaining stable blood pressure is one of the core goals of intraoperative hemodynamic management. ${ }^{4}$ Although intraoperative hypotension is assumed to be associated with postoperative mortality, the threshold value of the blood pressure remains undefined, especially in the geriatric population. ${ }^{5}$ Therefore, it is of important clinical value to define the safe range of intraoperative blood pressure in elderly patients and regard it as one of the management objectives of hemodynamics. The purpose of this study is to investigate the correlation between the level and duration of intraoperative blood pressure and postoperative death in elderly patients and to explore other potential risk factors related to postoperative death in elderly patients.

\section{Materials and Methods}

\section{Study Design and Population}

This was a retrospective investigation study in three centers. The study was approved and the written informed consent was waived by the Ethics Committee of the First Affiliated Hospital (Southwest Hospital) of Army Medical University, PLA [KY2020182], by the Medical Ethics Committee of Second Affiliated Hospital (Xinqiao Hospital) of Army Medical University, PLA [2020-119-01] and by the Ethics Committee of Army Specialty Medical Center (Daping Hospital) of Army Medical University, PLA [2020.No.147] respectively. This study has been retrospectively registered in the Chinese Clinical Trials Registry (ChiCTR2000038912, 10/10/2020).

The inclusion criteria are as follows: the age of patients are $\geq 65$ years old; the ASA Grade is I-IV; non-cardiac surgery; the operation time is more than 1 hour; the anesthetic methods are general anesthesia without combination with other anesthesia methods, spinal anesthesia or nerve block anesthesia; with definite clinical outcomes: cured, improved or died in the hospital. Died in the hospital after the operation within 60 days is defined as postoperative mortality. The transplantation surgery and adrenalectomy were excluded.
From September 2014 to March 2017, 31,654 cases met the inclusion and exclusion criteria. Having a postoperative mortality event, 118 cases were included in the Observational group, and the Control group was propensity matched by quantity from the survival cases. The number of surviving cases was twice as many as the Observational group in seven types of non-cardiac surgery (See Figure 1).

\section{Collection and Collation of Blood Pressure Data}

The intraoperative blood pressure data stored through the Mediston Anesthesia Information system (Mediston Medical Technology Company, Suzhou, China) were collected without distinction between noninvasive blood pressure and invasive blood pressure.

According to related studies, MAP $\leq 55 \mathrm{mmHg}$ and $\mathrm{SBP} \leq 80 \mathrm{mmHg}$ can be regarded as intraoperative hypotension, while MAP $>75 \mathrm{mmHg}$ and $\mathrm{SBP}>120 \mathrm{mmHg}$ are considered as nonhypotension thresholds. ${ }^{6,7}$ However, in order to explore a more accurate threshold of intraoperative hypotension in elderly patients, the researchers set the $\mathrm{MAP}$ analysis range to $5 \mathrm{mmg}$ and the $\mathrm{SBP}$ analysis range to $10 \mathrm{mmHg}$ for further study.

The blood pressure values, from anesthesia induction to the end of anesthesia, were collected and analyzed. According to the research scope of blood pressure above, the total number of minutes of SBP and MAP in the different range were calculated. The duration of SBP and MAP were recorded every 5 minutes and the invasive blood pressure was preferably selected for analysis. The blood pressure value at some time point, if obviously wrong or missing, would be replaced by the value recorded at the previous time point. In addition, the proportions of duration to the total operation time were measured.

To better realize the Logistic regression analysis, with reference of the ratio of blood pressure duration in each section to the total operation time, intraoperative blood pressure was defined as sort variables.

By analyzing the proportion of the duration of each blood pressure scope to the total operation time in the two groups, respectively, ratios of $0 \%$ and $10 \%$ were selected as the critical points. The ratio of $0 \%$ was defined as the variable 1 , the ratio greater than $10 \%$ was defined as the variable 3 , and the ratio between $0 \%$ and $10 \%$ was defined as the variable 2. These two critical points define intraoperative blood pressure as three categorical variables, and the distribution of 


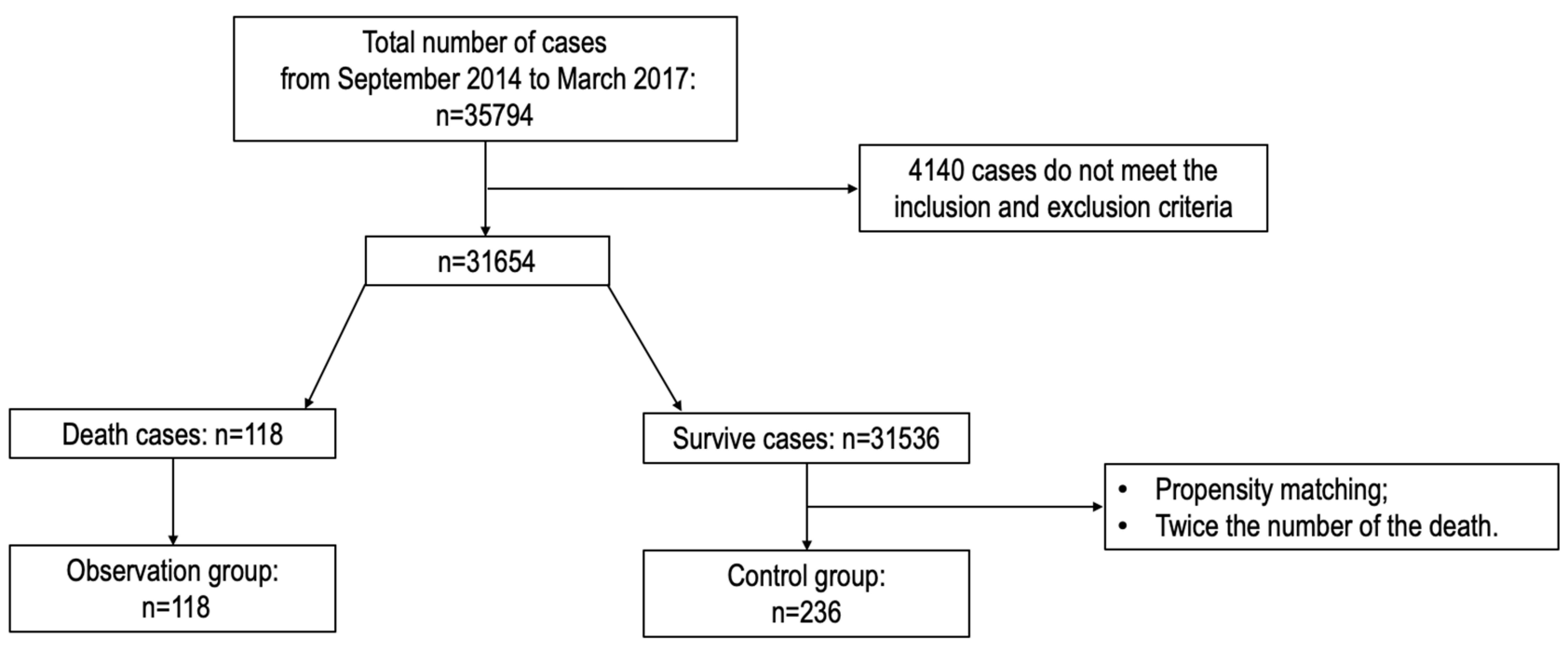

Figure I The flow chart of patient enrollment. Control group $(n=236)$, Observational group $(n=|| 8)$.

the three variables is roughly balanced, which can better achieve multi-factor logistics regression.

\section{Collection and Collation of Other Clinical Data}

The clinical information, including blood pressure (MAP and SBP), gender, age, body mass index (BMI), ASA grade, NYHA heart function, operation type, operation time, anesthesia method, co-morbidity (hypertension, coronary heart disease, cerebral hernia, arrhythmia, diabetes, renal dysfunction, chronic obstructive pulmonary disease (COPD), anemia, trauma, malignant tumor), Charlson index, PACU therapy, intraoperative use of vasoactive drugs, intraoperative blood loss volume, Intraoperative urine output volume, intraoperative blood transfusion volume, intraoperative crystal liquid infusion, intraoperative colloidal fluid infusion, total intraoperative infusion, intraoperative resuscitation, and postoperative information were objectively extracted from the medical record system. Among these variables, Age, BMI, intraoperative blood loss volume, intraoperative urine output volume, intraoperative blood transfusion volume, intraoperative crystal liquid infusion, intraoperative colloidal fluid infusion, and total intraoperative infusion were regarded as continuous variables, the other variables were taken as sort variables. ASA grade, NYHA heart function were defined as 4 classification variables in accordance with existing classification standards. The mode of anesthesia is defined as two classification variables, including general anesthesia and non-general anesthesia. The other parameters were all seen as 2 classification variables: used or unused. Postoperative information were not used for univariate or multiple logistic regression analysis.

\section{Statistical Analysis}

SPSS 18.0 software (SPSS, Chicago, Illinois, USA) was used to complete statistical analysis. The counting data were expressed using frequency and percentage, and the Chi-square test is used to compare between the two groups. Measurement data is represented by the median and quartile spacing [M (P25 P75)], Mann-Whitney $U$-test is used to compare between the two groups.

The blood pressure and the perioperative clinical indicators of elderly patients were analyzed by univariate logistic regression analysis firstly, and then the indicators with $p<0.05$ were further analyzed by multiple logistic regression (stepwise regression method, entry: $P=0.05$; removal $P=0.10$ ). The linear model was used to diagnose the collinearity of the variables.

At last, the receiver operating characteristic (ROC) curve was established through multivariate regression analysis, which was used to analyze the sensitivity and specificity and determine the critical value.

\section{Result}

The Postoperative Mortality of Elderly Patients Undergoing Noncardiac Surgery in Three Hospitals

From September 2014 to March 2017, the postoperative mortality rate of the elderly patients in the three 
Table I Clinical Characteristics of Patients

\begin{tabular}{|c|c|c|c|c|}
\hline & Control Group $(n=236)$ & Observational Group (n=||8) & Statistic & $p$ value \\
\hline \multicolumn{5}{|l|}{ Demographics } \\
\hline Age $[M(P 25, P 75)]$ & $71(68-77)$ & $72(68-79)$ & -1.75 & 0.079 \\
\hline Male, n (\%) & I $35(57.20)$ & $78(66.10)$ & 2.60 & 0.107 \\
\hline BMI $[M(P 25, P 75)]$ & $22.9(21.0-25.4)$ & $22.3(19.8-24.8)$ & -1.77 & 0.076 \\
\hline ASA classification, $n(\%)$ & & & 82.65 & $<0.001^{*}$ \\
\hline 1 & $9(3.8 \mathrm{l})$ & $\mathrm{I}(0.85)$ & & \\
\hline II & $173(73.31)$ & $37(31.36)$ & & \\
\hline III & $51(21.6 I)$ & $54(45.76)$ & & \\
\hline IV & $3(1.27)$ & $26(22.03)$ & & \\
\hline NYHA cardiac function, $\mathrm{n}(\%)$ & & & 5.08 & 0.079 \\
\hline 1 & $29(12.29)$ & $10(8.47)$ & & \\
\hline ॥ & $161(68.22)$ & $73(61.86)$ & & \\
\hline III & $46(19.49)$ & $35(29.66)$ & & \\
\hline \multicolumn{5}{|l|}{ Co-morbidity } \\
\hline Hypertension, n (\%) & $102(43.22)$ & $60(50.85)$ & 1.84 & 0.175 \\
\hline CHD, n (\%) & $38(16.10)$ & $24(20.34)$ & 0.98 & 0.323 \\
\hline Cerebral hernia, n (\%) & I (0.42) & $8(6.78)$ & 12.83 & $<0.001^{*}$ \\
\hline Arrhythmia, n (\%) & $28(11.86)$ & II (9.32) & 0.52 & 0.471 \\
\hline Diabetes, n (\%) & $39(16.53)$ & $23(19.49)$ & 0.48 & 0.489 \\
\hline Renal dysfunction, $\mathrm{n}(\%)$ & $0(0.00)$ & $8(6.78)$ & 13.44 & $<0.001 *$ \\
\hline COPD, n (\%) & $8(3.39)$ & $15(12.82)$ & 11.42 & $0.001 *$ \\
\hline Anemia, $n(\%)$ & $19(8.05)$ & $6(5.08)$ & 1.05 & 0.304 \\
\hline Trauma, n (\%) & $3(1.28)$ & $14(11.86)$ & 19.21 & $<0.001^{*}$ \\
\hline Malignant tumor, n (\%) & 67 (28.39) & $31(26.27)$ & 0.18 & 0.675 \\
\hline Charlson index & $\mathrm{I}(0,2)$ & $2(1,2)$ & -2.796 & $0.005^{*}$ \\
\hline \multicolumn{5}{|l|}{ Surgery information } \\
\hline Intraoperative Crystal liquid infusion (mL) [M (P25, P75)] & $1250(800,1787.5)$ & $1500(675,2162.5)$ & -0.839 & 0.401 \\
\hline Intraoperative Colloidal fluid infusion (mL) [M (P25, P75)] & $500(500,500)$ & $800(500,800)$ & -6.667 & $<0.001^{*}$ \\
\hline Total intraoperative infusion $(\mathrm{mL})[\mathrm{M}(\mathrm{P} 25, \mathrm{P} 75)]$ & $1800(1400,2400)$ & $2375(1575,3200)$ & -3.899 & $<0.001^{*}$ \\
\hline Intraoperative blood loss (mL) [M (P25, P75)] & $20(100,200)$ & $200(100,400)$ & -5.181 & $<0.00 I^{*}$ \\
\hline Intraoperative blood transfusion volume $(\mathrm{mL})[\mathrm{M}(\mathrm{P} 25, \mathrm{P} 75)]$ & $0(0,0)$ & $0(0,732.5)$ & -4.896 & $<0.001^{*}$ \\
\hline Intraoperative urine volume $(\mathrm{mL})[\mathrm{M}(\mathrm{P} 25, \mathrm{P} 75)]$ & $200(0,500)$ & $300(100,600)$ & -2.779 & $0.005^{*}$ \\
\hline Emergency operation, $n(\%)$ & $21(8.90)$ & $58(49.15)$ & 73.53 & $<0.001^{*}$ \\
\hline Operation time $(\mathrm{min})[\mathrm{M}(\mathrm{P} 25, \mathrm{P} 75)]$ & $172.5(120,238.75)$ & $220(143.75,331.25)$ & -4.199 & $<0.001^{*}$ \\
\hline PACU therapy, n (\%) & $157(66.53)$ & $5 I(43.22)$ & 17.63 & $<0.001^{*}$ \\
\hline The use of vasoactive drugs, $\mathrm{n}(\%)$ & $68(28.81)$ & $58(49.15)$ & 14.20 & $<0.001^{*}$ \\
\hline General anesthesia, $\mathrm{n}(\%)$ & $|7|(72.46)$ & $112(94.92)$ & 24.75 & $<0.001^{*}$ \\
\hline Intraoperative resuscitation, $\mathrm{n}(\%)$ & I (0.42) & $5(4.24)$ & 4.768 & $0.029 *$ \\
\hline Type of surgery, n (\%) & & & 0.000 & $>0.999$ \\
\hline Neurosurgery & $36(15.25)$ & $18(15.25)$ & & \\
\hline General surgery & $32(13.56)$ & $16(13.56)$ & & \\
\hline Hepatobiliary Surgery & $34(14.4 I)$ & $17(14.41)$ & & \\
\hline Urological surgery & $28(11.86)$ & $14(11.86)$ & & \\
\hline Thoracic surgery & $36(15.25)$ & $18(15.25)$ & & \\
\hline Orthopedic surgery & $38(16.10)$ & $19(16.10)$ & & \\
\hline Obstetrics and Gynecology Surgery & $32(13.56)$ & $16(13.56)$ & & \\
\hline \multicolumn{5}{|l|}{ Postoperative information } \\
\hline Postoperative ICU therapy, n (\%) & $4(1.69)$ & $23(19.49)$ & 32.883 & $<0.00 I^{*}$ \\
\hline Postoperative hospitalization (days) [M (P25, P75)] & $18(11,24)$ & $9(3,23.5)$ & -4.952 & $<0.001^{*}$ \\
\hline Second post-operative surgery, n (\%) & $6(2.54)$ & II (9.32) & 7.909 & $0.005 *$ \\
\hline
\end{tabular}

(Continued) 
Table I (Continued).

\begin{tabular}{|c|c|c|c|c|}
\hline & Control Group $(n=236)$ & Observational Group ( $n=118)$ & Statistic & $p$ value \\
\hline \multicolumn{5}{|c|}{ Postoperative organ dysfunction, $n$ (\%) } \\
\hline Postoperative AKI & $2(0.85)$ & $9(7.62)$ & 9.863 & $0.002 *$ \\
\hline Postoperative ARDS & $2(0.85)$ & $5(4.24)$ & 3.079 & 0.079 \\
\hline Postoperative delirium & $\mathrm{I}(0.42)$ & $3(2.54)$ & 1.549 & 0.213 \\
\hline Postoperative stroke & $0(0.00)$ & $4(3.39)$ & 8.881 & $0.012^{*}$ \\
\hline
\end{tabular}

Note: ${ }^{*} p<0.05$ was statistically significant.

Abbreviations: BMI, body mass index; ASA, American Society of Anesthesiologists; NYHA, New York Heart Association; CHD, coronary heart disease; COPD, chronic obstructive pulmonary disease; PACU, postanesthesia care unit; ICU, intensive care unit; AKI, acute kidney injury; ARDS, acute respiratory distress syndrome.

hospitals was 3.3\%o. Compared with the Control group, the proportion of comorbidity with cerebral hernia, renal failure and trauma was $6.78 \%, 6.78 \%$ and $11.86 \%$ respectively in the Observational group, which are higher than the ration in the Control group ( $p<$ 0.001 ), accordingly the Charlson index is higher in the Observation group than the Control group $(p=0.005)$. The proportion of using vasoactive drugs and general anesthesia was also higher in the Observational group, the ration is $49.15 \%$ and $94.92 \%$, respectively ( $p<$ 0.001). There was also significant difference in the amount of intraoperative blood transfusion and blood loss volume between the two groups $(p<0.001)$. Compared with the Control group, the Observational group had more intraoperative colloidal fluid infusion $(p<0.001)$, total intraoperative infusion $(p<0.001)$ and intraoperative urine output volume $(p=0.005)$. After the operation, more patients in the Observation group were transmitted to the ICU $(p<0.001)$ and suffered the second postoperative surgery $(p=0.005)$. There were more patients in the Observation group diagnosed with postoperative AKI $(p=0.002)$ and postoperative stroke $(p=0.012)$. Compared with the Observation group, patients in the Control group had experienced a longer postoperative hospitalization $(p<0.001)$ (See Table 1).

\section{The Blood Pressure in Each Section Between Two Groups}

The duration of MAP and SBP in different blood pressure ranges was calculated respectively, and their proportion to the total operation time was expressed as the median and quartile spacing $M$ (P25, P75) (see Tables 2 and 3). Compared with the Observational group, the median blood pressure duration ratio of the Control group was higher at the blood pressure interval of MAP $\geq 75 \mathrm{mmHg}$.

\section{The Result of Univariate Logistic Regression Analysis}

Univariate logistic regression analysis was used to analyze the potential relationship among intraoperative blood pressure, other clinical indicator, and postoperative mortality. The results indicated that some blood pressure sections, including MAP $(\mathrm{MAP} \leq 55 \mathrm{mmHg}, 55 \mathrm{mmHg}<\mathrm{MAP} \leq$

Table 2 Percentage of Cumulative Duration of MAP in Total Operation Time [\%, M (P25, P75)]

\begin{tabular}{|c|c|c|c|c|c|c|}
\hline Group & $\leq 55 \mathrm{mmHg}$ & $>55 \sim 60 \mathrm{mmHg}$ & $>60 \sim 65 \mathrm{mmHg}$ & $>65 \sim 70 \mathrm{mmHg}$ & $>7 \mathrm{I} \sim 75 \mathrm{mmHg}$ & $>75 \mathrm{mmHg}$ \\
\hline Observational group & $0(0, I .84)$ & $0(0,4.13)$ & $4.92(0,10.78)$ & $8.82(1.44,15.94)$ & $12.27(4.42,19.34)$ & $63.78(44.23,90.38)$ \\
\hline Control group & $0(0,0)$ & $0(0,1.58)$ & $0(0,5.88)$ & $4.23(0,14.49)$ & $8.45(0,17.17)$ & $79.67(55.02,98.24)$ \\
\hline
\end{tabular}

Table 3 Percentage of SBP Cumulative Duration in Total Operation Time [\%, M (P25, P75)]

\begin{tabular}{|c|c|c|c|c|c|c|}
\hline Group & $\leq 80 \mathrm{mmHg}$ & $>80 \sim 90 \mathrm{mmHg}$ & $>90 \sim 100 \mathrm{mmHg}$ & $>100 \sim 110 \mathrm{mmHg}$ & $>110 \sim 120 \mathrm{mmHg}$ & $>120 \mathrm{mmHg}$ \\
\hline Observational group & $0(0,2.42)$ & $0(0,6)$ & $5.82(0,16.80)$ & $14.04(4.82,22.43)$ & $|5.2|(9.2,25.86)$ & $50.78(25.27,69.14)$ \\
\hline Control group & $0(0,0.4 \mathrm{I})$ & $0(0,3.30)$ & $4.51(0,15.31)$ & $12.29(1.72,25)$ & $17(7.14,27.92)$ & $50(22.73,81.7)$ \\
\hline
\end{tabular}


$60 \mathrm{mmHg}, 60 \mathrm{mmHg}<\mathrm{MAP} \leq 65 \mathrm{mmHg}, 65 \mathrm{mmHg}<\mathrm{MAP} \leq$ $70 \mathrm{mmHg}, 70 \mathrm{mmHg}<\mathrm{MAP} \leq 75 \mathrm{mmHg}$ ) and $\mathrm{SBP}(\mathrm{SBP} \leq$ $80 \mathrm{mmHg}, 80 \mathrm{mmHg}<\mathrm{BP} \leq 90 \mathrm{mmHg}$ ), might increase the postoperative mortality $(\mathrm{OR}>1)$. Other factors might be related to postoperative death of elderly patients $(p<0.05)$, such as ASA classification $(\mathrm{OR}=5.276,95 \% \mathrm{CI}, 3.504$ to 7.946), cardiac function classification $(\mathrm{OR}=1.546,95 \% \mathrm{CI}$, 1.042 to 2.295), method of general anesthesia $(\mathrm{OR}=7.096$, 95\% CI, 2.974 to 16.929), COPD (OR=4.191, 95\% CI, 1.772 to 10.199), Emergency operation $(\mathrm{OR}=9.897,95 \% \mathrm{CI}, 5.567$ to 17.594$)$, severe trauma $(\mathrm{OR}=10.41,95 \% \mathrm{CI}, 2.929$ to $37.003)$, intraoperative use of vasoactive drugs $(\mathrm{OR}=2.388$, 95\% CI, 1.511 to 3.775 ), intraoperative blood loss volume $(\mathrm{OR}=19.104,95 \% \mathrm{CI}, 8.716$ to 41.875$)$ and blood transfusion $(\mathrm{OR}=1.98,95 \% \mathrm{CI}, 1.151$ to 3.404$)$. $\mathrm{MAP}>75 \mathrm{mmHg}$ $(\mathrm{OR}=0.346,95 \% \mathrm{CI}, 0.123$ to 0.973$)$ and PACU therapy $(\mathrm{OR}=0.383,95 \% \mathrm{CI}, 0.243$ to 0.603$)$ may be seen as a protective factor (See Table 4 ).

\section{The Result of Multivariate Logistic Regression Analysis}

According to the statistically significant variables in the results of univariate analysis, six related factors affecting the postoperative death of elderly patients were obtained by multivariate Logistic regression analysis (See Table 5).

Five variables: emergency surgery, general anesthesia, COPD, ASA classification, and $60 \mathrm{mmHg}<\mathrm{MAP}$ $\leq 65 \mathrm{mmHg}$ were considered as risk factors for postoperative death in elderly patients $(\mathrm{OR}>1)$. Among them, the risk of emergency surgery is 2.2 times higher than that of elective surgery, the risk increases by 2.96 times for every increase in ASA classification level and patients with a history of COPD would have a 4.2 times higher risk for postoperative death. $60 \mathrm{mmHg}<\mathrm{MAP} \leq 65 \mathrm{mmHg}$ is a high-risk factor for postoperative death in elderly patients. When the proportion of MAP between $60 \mathrm{mmHg}$ and $65 \mathrm{mmHg}$ exceeds $10 \%$, the risk of postoperative death would increase by 1.5 to 2.25 times. Correspondingly, PACU therapy is a protective factor for postoperative death in elderly patients. The risk of postoperative death for patients observed by PACU was reduced by $80 \%$. $(\mathrm{OR}<1)$.

\section{ROC Curve and the Determination of the Optimal Critical Value of the Regression Model}

According to the results of multivariate regression analysis in Table 3, the regression equation is: $\mathrm{Y}=-5.893+0.815 \mathrm{X}_{1}$
$+1.086 \mathrm{X}_{2}+2.761 \mathrm{X}_{3}+0.409 \mathrm{X}_{4}+1.415 \mathrm{X}_{5}-1.472 \mathrm{X}_{6}$.

According to the above regression equation, $\mathrm{P}$ value of prediction probability of postoperative death of elderly patients is calculated, $P=1 / 1+\mathrm{e}^{-\mathrm{Y}}$. The ROC curve of $\mathrm{P}$ value is established (See Figure 2). The area under the curve (AUC) is 0.850 , and the $95 \%$ confidence interval (CI) is $(0.805,0.894)$. The optimal critical $\mathrm{P}$ value on the ROC curve is 0.338 , and the corresponding sensitivity and specificity are $73.5 \%$ and $82.2 \%$ respectively.

\section{Discussion}

In this logistic regression analysis study, we reported that MAP between $60 \mathrm{mmHg}$ and $65 \mathrm{mmHg}$ had a strong relationship with postoperative mortality in elderly patients. Additionally, ASA classification, emergency surgery, the method of general anesthesia, history of COPD were considered as high-risk factors $(\mathrm{OR}>1)$. By contrast, PACU therapy was considered as a protective factor. The area under the ROC curve is 0.850 , indicating that these clinical indicators are of great value in predicting postoperative mortality in elderly patients.

The result of this study on the lower threshold of intraoperative blood pressure in elderly patients is the most important achievement. The decrease in blood pressure during anesthesia and operation is inevitable. After the induction of general anesthesia, the circulatory inhibitory effects will make the peripheral vascular dilation and reduce peripheral vascular resistance; in spinal and regional anesthesia, the peripheral vascular will dilate as well. When the blood pressure decreases to some degree, it can be seen as intraoperative hypotension. In adult noncardiac surgery, some previous studies have suggested as follows: the morbidity of acute kidney injury and acute myocardial injury increased significantly when intraoperative MAP < $55 \mathrm{mmHg}$, even for a shorter duration; ${ }^{8,9}$ when the intraoperative MAP was 30\% lower than the basal blood pressure level, the incidence of postoperative stroke would increase, ${ }^{3}$ continuous MAP $<64 \mathrm{mmHg}$ was closely associated with stroke during cardiopulmonary bypass; ${ }^{7}$ in elderly patients with hypertension, the self-adjusting ability of the brain and kidneys may be impaired, causing the organs more prone to ischemia during hypotension. ${ }^{10,11}$ In current guidelines for noncardiac surgery, the American College of Cardiology (ACC) and the American Heart Association (AHA) recommends individualized management of surgical patients with preoperative complications. ${ }^{12}$ These studies and consensus highlight the importance of blood pressure management in reducing 
Table 4 Univariate Logistic Regression Analysis of Postoperative Mortality in Elderly Patients

\begin{tabular}{|c|c|c|c|c|c|c|}
\hline & $\begin{array}{l}\text { Regression } \\
\text { Coefficient (B) }\end{array}$ & $\begin{array}{l}\text { The Standard } \\
\text { Deviation (SE) }\end{array}$ & $\begin{array}{l}\text { Wald } \\
\text { Value }\end{array}$ & $\mathbf{P}$ & $\begin{array}{l}\text { The OR } \\
\text { Value }\end{array}$ & $95 \% \mathrm{Cl}$ \\
\hline Age & 0.197 & 0.151 & 1.710 & 0.191 & 1.218 & $0.906 \sim 1.637$ \\
\hline Gender & 0.378 & 0.235 & 2.587 & 0.108 & 1.459 & $0.921 \sim 2.311$ \\
\hline Body mass index (BMI) & 0.066 & 0.035 & 3.458 & 0.063 & 0.936 & $0.873 \sim 1.004$ \\
\hline ASA classification & 1.663 & 0.209 & 63.411 & $<0.001 *$ & 5.276 & $3.504 \sim 7.946$ \\
\hline NYHA cardiac function & 0.436 & 0.202 & 4.675 & $0.031 *$ & 1.546 & $\mathrm{I} .042 \sim 2.295$ \\
\hline Hypertension & 0.307 & 0.226 & 1.839 & 0.175 & 1.359 & $0.872 \sim 2.117$ \\
\hline CHD & 0.285 & 0.289 & 0.974 & 0.324 & 1.330 & $0.755 \sim 2.345$ \\
\hline Cerebral hernia & 2.839 & 1.067 & 7.078 & $0.008^{*}$ & $|7.09|$ & $2.111 \sim 138.338$ \\
\hline Arrhythmia & 0.270 & 0.375 & 0.516 & 0.472 & 0.764 & $0.366 \sim 1.593$ \\
\hline Diabetes & 0.201 & 0.291 & 0.478 & 0.489 & 1.223 & $0.691 \sim 2.164$ \\
\hline COPD & 1.433 & 0.454 & 9.975 & $0.002 *$ & 4.191 & $1.722 \sim 10.199$ \\
\hline Anemia & 0.491 & 0.483 & 1.037 & 0.309 & 0.612 & $0.238 \sim 1.575$ \\
\hline Trauma & 2.343 & 0.647 & 13.109 & $<0.001^{*}$ & 10.41 & $2.929 \sim 37.003$ \\
\hline Malignant tumor & 0.107 & 0.254 & 0.176 & 0.675 & 0.899 & $0.546 \sim 1.479$ \\
\hline \multicolumn{7}{|l|}{ Blood pressure } \\
\hline $\mathrm{MAP} \leq 55 \mathrm{mmHg}$ & 0.557 & 0.201 & 7.696 & $0.006 *$ & 1.745 & I. I $78 \sim 2.587$ \\
\hline $55<\mathrm{MAP} \leq 60 \mathrm{mmHg}$ & 0.357 & 0.179 & 3.996 & $0.046^{*}$ & 1.430 & $1.007 \sim 2.030$ \\
\hline $60<\mathrm{MAP} \leq 65 \mathrm{mmHg}$ & 0.537 & 0.150 & 12.809 & $<0.001 *$ & 1.712 & $\mathrm{I} .275 \sim 2.297$ \\
\hline $65<\mathrm{MAP} \leq 70 \mathrm{mmHg}$ & 0.381 & 0.134 & 8.013 & $0.005^{*}$ & 1.463 & $1.124 \sim 1.905$ \\
\hline $70<\mathrm{MAP} \leq 75 \mathrm{mmHg}$ & 0.373 & 0.145 & 6.600 & $0.010^{*}$ & 1.452 & $1.092 \sim 1.929$ \\
\hline $\mathrm{MAP}>75 \mathrm{mmHg}$ & 1.061 & 0.527 & 4.050 & $0.044^{*}$ & 0.346 & $0.123 \sim 0.973$ \\
\hline $\mathrm{SBP} \leq 80 \mathrm{mmHg}$ & 0.413 & 0.205 & 4.069 & $0.044^{*}$ & 1.511 & $1.012 \sim 2.258$ \\
\hline $80<\mathrm{SBP} \leq 90 \mathrm{mmHg}$ & 0.342 & 0.156 & 4.849 & $0.028^{*}$ & 1.408 & $1.038 \sim 1.910$ \\
\hline $90<\mathrm{SBP} \leq 100 \mathrm{mmHg}$ & 0.094 & 0.133 & 0.500 & 0.480 & 1.098 & $0.847 \sim 1.425$ \\
\hline $100<\mathrm{SBP} \leq 110 \mathrm{mmHg}$ & 0.252 & 0.144 & 3.058 & 0.080 & 1.286 & $0.970 \sim 1.705$ \\
\hline $110<\mathrm{SBP} \leq 120 \mathrm{mmHg}$ & 0.168 & 0.165 & 1.027 & 0.311 & 1.183 & $0.855 \sim 1.635$ \\
\hline $\mathrm{SBP}>120 \mathrm{mmHg}$ & 0.198 & 0.229 & 0.748 & 0.387 & 1.219 & $0.778 \sim 1.912$ \\
\hline General anesthesia & 1.959 & 0.444 & 19.507 & $<0.00 I^{*}$ & 7.096 & $2.974 \sim 16.929$ \\
\hline Emergency operation & 2.292 & 0.294 & 60.969 & $<0.001 *$ & 9.897 & $5.567 \sim 17.594$ \\
\hline PACU therapy & 0.960 & 0.231 & 17.195 & $<0.001 *$ & 0.383 & $0.243 \sim 0.603$ \\
\hline The use of vasoactive drugs & 0.871 & 0.234 & 13.889 & $<0.001 *$ & 2.388 & $1.5 \mathrm{II} \sim 3.775$ \\
\hline Intraoperative urinary volume & 0.062 & 0.248 & 0.062 & 0.803 & 0.940 & $0.578 \sim 1.528$ \\
\hline Intraoperative blood loss & 2.950 & 0.400 & 54.278 & $<0.00 I^{*}$ & 19.104 & $8.716 \sim 41.875$ \\
\hline $\begin{array}{l}\text { Intraoperative blood } \\
\text { transfusion volume }\end{array}$ & 0.683 & 0.277 & 6.093 & $0.014^{*}$ & 1.980 & $1.151 \sim 3.404$ \\
\hline
\end{tabular}

Note: $*_{p}<0.05$ was statistically significant.

Abbreviations: BMI, body mass index; ASA, American Society of Anesthesiologists; NYHA, New York Heart Association; CHD, coronary heart disease; COPD, chronic obstructive pulmonary disease; PACU, postanesthesia care unit; ICU, intensive care unit; AKI, acute kidney injury; ARDS, acute respiratory distress syndrome. 
Table 5 Multivariate Logistic Regression Analysis of Postoperative Mortality in Elderly Patients

\begin{tabular}{|c|c|c|c|c|c|c|}
\hline Variable & $\begin{array}{c}\text { Regression } \\
\text { Coefficient (B) }\end{array}$ & $\begin{array}{l}\text { The Standard } \\
\text { Deviation (SE) }\end{array}$ & $\begin{array}{l}\text { Wald } \\
\text { Value }\end{array}$ & $P$ & $\begin{array}{l}\text { The OR } \\
\text { Value }\end{array}$ & $95 \% \mathrm{Cl}$ \\
\hline$X_{1}$ Emergency operation & 0.815 & 0.403 & 4.089 & 0.043 & 2.260 & $1.025 \sim 4.982$ \\
\hline $\mathrm{X}_{2}$ ASA classification & 1.086 & 0.278 & 15.276 & $<0.001$ & 2.963 & $1.719 \sim 5.109$ \\
\hline $\mathrm{X}_{3}$ General anesthesia & 2.761 & 0.570 & 23.428 & $<0.001$ & 15.819 & $5.17|\sim 48.39|$ \\
\hline$X_{4} 60 \mathrm{mmHg}<M A P \leq 65 \mathrm{mmHg}$ & 0.409 & 0.197 & 4.305 & 0.038 & 1.505 & $1.023 \sim 2.215$ \\
\hline$X_{5}$ COPD & 1.415 & 0.569 & 6.186 & 0.013 & 4.117 & $1.350 \sim 12.557$ \\
\hline $\mathrm{X}_{6}$ PACU therapy & -1.472 & 0.363 & 16.404 & $<0.001$ & 0.230 & $0.113 \sim 0.468$ \\
\hline Constant & -5.893 & 0.911 & 41.828 & $<0.001$ & 0.003 & \\
\hline
\end{tabular}

Note: $p<0.05$ was statistically significant.

postoperative mortality and improving prognosis in elderly patients. However, there is no existing consensus on the maintenance range of blood pressure in elderly patients. From this point of view, our study provides evidence for clarifying the goal of blood pressure management in elderly patients. Our study regards the MAP between 60 and $65 \mathrm{mmHg}$ as a risk factor for postoperative mortality in elderly patients. Although the results of our study did not show the correlation between MAP below $60 \mathrm{mmHg}$ and the postoperative mortality, combined with the theory of ischemia-reperfusion injury caused by hypotension, it can be inferred that MAP below $60 \mathrm{mmHg}$ may also affect postoperative mortality of elderly patients. A recent metaanalysis indicated that intraoperative hypotension was associated with an increased risk of postoperative AKI,

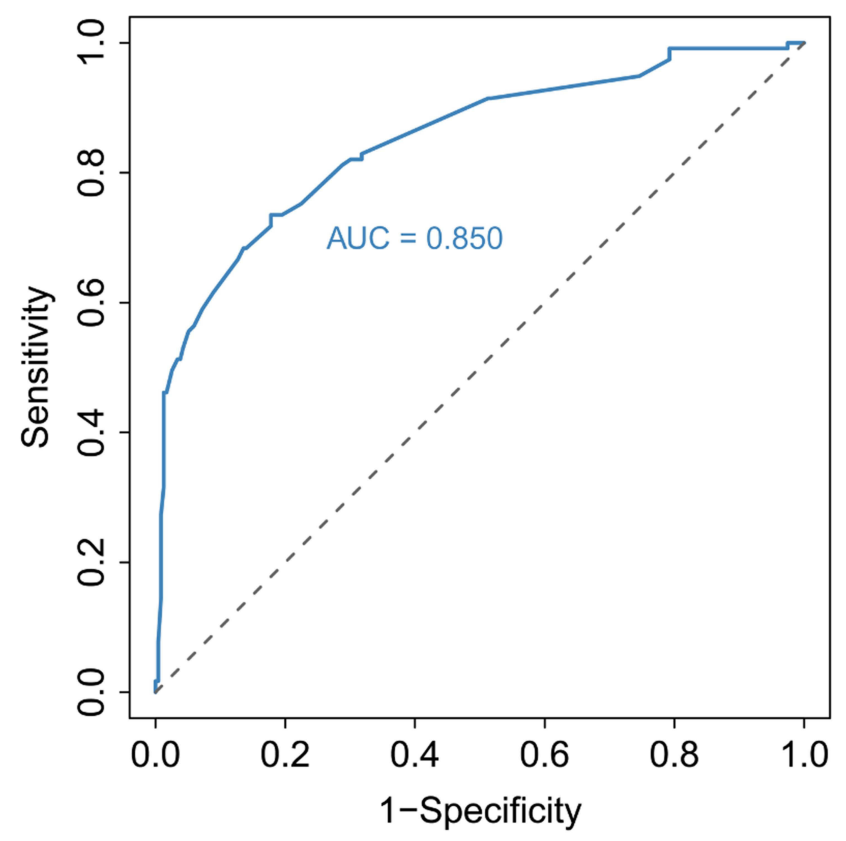

Figure 2 The ROC curve of $\mathrm{P}$ value predicted by logistic regression mode and the area under the curve (AUC). myocardial injury and 30-day mortality in non-cardiac surgery and suggested that intraoperative MAP $<60$ mmHg should be avoided. ${ }^{13}$ So maybe MAP $=65 \mathrm{mmHg}$ can be regarded as the lower threshold of intraoperative blood pressure in elderly patients undergoing noncardiac surgery. When intraoperative MAP $\leq 65 \mathrm{mmHg}$, it can be called an intraoperative hypotension event, which is a risk factor of postoperative mortality in elderly patients. It has been reported in adult noncardiac surgery that the duration of MAP $<49 \mathrm{mmHg}$ more than 5 minutes may increase the outcome of 30-day postoperative mortality. ${ }^{5}$ Our results of this study suggest that the threshold of intraoperative hypotension in elderly patients is $65 \mathrm{mmHg}$, which is higher than that of $49 \mathrm{mmHg}$. The reason behind this difference may be that the vascular system of elderly patients is more fragile and the ability of self-regulation is reduced. It is known that renal blood flow and glomerular filtration rate can keep stable when the MAP is in the range of $75-170 \mathrm{mmHg},{ }^{14}$ however these indicates will become pressure-dependent once MAP beyond the range. Our study also indicates that the Observation group has a higher incidence of postoperative AKI, which may be related to the postoperative mortality rate. Therefore, MAP $>65 \mathrm{mmHg}$ should be maintained as far as possible in the perioperative circulation management of elderly patients.

The definition of intraoperative hypotension has not yet been unified. The absolute and relative definition of intraoperative hypotension have all been used in researches. ${ }^{8}$ Our study did not choose to use a relative intraoperative hypotension which may have a $20-40 \%$ drop in intraoperative blood pressure compared with preoperative blood pressure, based on the following considerations: Firstly, this study is a retrospective study, it is difficult to determine the accurate preoperative blood pressure; secondly, the relative intraoperative hypotension has not yet been unified and determined; thirdly, studies 
have found that it would be feasible and beneficial to use the absolute value as the lower limit of intraoperative hypotension, it would be more easily for anesthesiologists to master and to incorporate into their clinical decision systems.

The results of our study about the high-risk factor, ASA grade, emergency surgery, as well as the protective factor, PACU therapy, in elderly patients are consistent with the current point of view and practice. According to the definition of ASA grade, the higher the ASA grade, the higher the anesthetic risk and postoperative mortality. Emergency surgery has been reported as an independent risk factor for postoperative mortality. And the significance of PACU therapy is to pay close attention to postoperative patients reducing the incidence of adverse prognosis.

COPD is estimated to be the third leading cause of death worldwide by $2020 .^{15}$ Recent studies demonstrated that pneumonia and COPD individually affected the 30day mortality and total mortality, ${ }^{16}$ which is consistent with our study. Elderly patients not only have a high incidence of COPD but also have a higher risk of postoperative mortality than young COPD patients. ${ }^{17}$ COPD is characterized by persistent airflow limitation, which in turn affects gas exchange, in severe cases, can lead to pulmonary hypertension and develop into cor pulmonale. Anesthetic drugs and anesthetic methods will inevitably affect the respiratory function of patients, not to mention the effects of surgical posture and other factors on the respiratory function of patients. ${ }^{18}$ It has been reported that postoperative pulmonary complications in patients with COPD are increased, and the occurrence of postoperative pulmonary complications is a high-risk factor for postoperative death. ${ }^{19,20}$ This is consistent with our findings that preoperative COPD is a high-risk factor for postoperative death in elderly patients. At present, the understanding of anesthetic management of elderly patients with COPD is still insufficient, our study highlights the necessity of paying attention to perioperative elderly patients with COPD and provides ideas for further research.

Our results demonstrate that general anesthesia is a risk factor about the postoperative mortality, so sufficient vigilance should be maintained in the choice of anesthetic methods for elderly patients. The choice and the safety of different anesthesia methods are still controversial. For geriatric patients undergoing hip surgery, nerve blocking anesthesia was associated with fewer odds of adverse outcomes than general anesthesia. ${ }^{21}$ Some studies have shown that the use of regional anesthesia in patients with COPD is associated with lower incidences of composite morbidity, pneumonia, prolonged ventilator dependence, and unplanned postoperative intubation. ${ }^{22,23}$ From the results of our research, On the premise of meeting the surgical needs, avoiding general anesthesia for elderly patients may reduce postoperative mortality and improve the outcome. The results of our study also provide objective evidence for anesthesiologists to choose the method of anesthesia in the face of elderly patients.

Our study also has some limitations. Firstly, six related factors were obtained by multi-factor logistic analysis, which shows that the sample size is sufficient. However, a large number of variables are included in the univariate logistic regression analysis, which indicates that the sample size may be a little small. Secondly, there is a difference in the duration of operation between the Observation group and the Control group. The analysis of blood pressure is based on the proportion of the duration of each blood pressure segment, and the threshold of the duration of intraoperative hypotension can not be obtained. Thirdly, we explored the threshold of hypotension in elderly patients, but the impact of hypotension on the function of important organs is not confirmed by laboratory indicators.

\section{Conclusions}

Elderly patients are vulnerable groups, combined with our research results, attention should be paid to patients undergoing emergency surgery, with high ASA grade, and with a history of COPD. The mode of anesthesia should be prudently chosen and the MAP should be maintained above $65 \mathrm{mmHg}$ intraoperatively. Optimizing the perioperative management of elderly patients is the key point to reduce the mortality of geriatric patients.

\section{Abbreviations}

95\% CI, 95\% confidence interval; ASA, American Society of Anesthesiologists; AUC, Area under the curve; $\mathrm{IOH}$, intraoperative hypotension; COPD, chronic obstructive pulmonary disease; PACU, postanesthesia care unit; ROC, Receiver operating characteristic; RR, Risk ratio; MAP, mean arterial pressure; SBP, systolic blood pressure; MODS, multiple organs dysfunction syndrome; OR, odds ratio; $\mathrm{ACC}$, American College of Cardiology; AHA, American Heart 
Association. BMI, Body Mass Index; NYHA, New York Heart Association; CHD, Coronary Heart Disease; ICU, Intensive Care Unit; AKI, Acute Kidney Injury; ARDS, Acute Respiratory Distress Syndrome.

\section{Data Sharing Statement}

The datasets used and/or analysed during the current study are available from the corresponding author, Jianteng $\mathrm{Gu}$, on reasonable request.

\section{Ethics Approval and Consent to Participate}

The study was approved and the written informed consent was waived by the Ethics Committee of the First Affiliated Hospital (Southwest Hospital) of Army Medical University, PLA [KY2020182], by the Medical Ethics Committee of Second Affiliated Hospital (Xinqiao Hospital) of Army Medical University, PLA [2020-119-01] and by the Ethics Committee of Army Specialty Medical Center (Daping Hospital) of Army Medical University, PLA [2020.No.147] respectively. This study has been retrospectively registered in the Chinese Clinical Trials Registry (ChiCTR2000038912, 10/10/2020). All methods performed in this study were in accordance with the relevant guidelines and regulations. All procedures performed in this study involving human participants were in accordance with the Ethical Standards of the Institutional Ethics Committee and with the 1964 Helsinki Declaration and its later amendments or comparable ethical standards.

\section{Acknowledgments}

The authors would like to thank Professor Daqing $\mathrm{Ma}$, Division of Anaesthetics, Pain Medicine \& Intensive Care, Imperial College London for spending his valuable time on reading the manuscript and providing valuable suggestions. We appreciate the support from the National Key R\&D Program of China (No. 2018YFC0116703) and the Excellent Talents Foundation of Army Medical University (XZ-2019-505-028). Benhui Zhao and Xingtong Chen are co-first authors for this study.

\section{Funding}

This study was supported by the National Key R\&D Program of China (No. 2018YFC0116703) and the Excellent Talents Foundation of Army Medical University (XZ-2019-505-028). The funding agencies had no direct role in the conduct of the study; the collection, management, analyses, or interpretation of the data; or preparation or approval of the manuscript.

\section{Disclosure}

The authors report no conflicts of interest in this work.

\section{References}

1. Lutz W, Sanderson W, Scherbov S. The coming acceleration of global population ageing. Nature. 2008;451(7179):716-719. doi:10. 1038/nature06516

2. Lu WL, Kumar SDS, Zheng SB. A single-centre based analysis of hospitalized elderly surgical patients and the related perioperative mortality. 3rd Chinese Congress on Gerontology and Health Industry (CCGI); 2014

3. Bijker JB, Persoon S, Peelen LM, et al. Intraoperative hypotension and perioperative ischemic stroke after general surgery: a nested case-control study. Anesthesiology. 2012;116(3):658-664. doi:10. 1097/ALN.0b013e3182472320

4. Südfeld S, Brechnitz S, Wagner JY, et al. Post-induction hypotension and early intraoperative hypotension associated with general anaesthesia. Br J Anaesth. 2017;119(1):57-64. doi:10.1093/bja/ aex 127

5. Monk TG, Bronsert MR, Henderson WG, et al. Association between intraoperative hypotension and hypertension and 30-day postoperative mortality in noncardiac surgery. Anesthesiology. 2015;123 (2):307-319. doi:10.1097/ALN.0000000000000756

6. Salmasi V, Maheshwari K, Yang D, et al. Relationship between intraoperative hypotension, defined by either reduction from baseline or absolute thresholds, and acute kidney and myocardial injury after noncardiac surgery: a retrospective cohort analysis. Anesthesiology. 2017;126(1):47-65. doi:10.1097/ALN.00000000 00001432

7. Sun LY, Chung AM, Farkouh ME, et al. Defining an intraoperative hypotension threshold in association with stroke in cardiac surgery. Anesthesiology. 2018;129(3):440-447. doi:10.1097/ALN.000000000 0002298

8. Wesselink EM, Kappen TH, Torn HM, Slooter AJC, van Klei WA. Intraoperative hypotension and the risk of postoperative adverse outcomes: a systematic review. Br J Anaesth. 2018;121(4):706-721. doi:10.1016/j.bja.2018.04.036

9. Walsh M, Devereaux PJ, Garg AX, et al. Relationship between intraoperative mean arterial pressure and clinical outcomes after noncardiac surgery: toward an empirical definition of hypotension. Anesthesiology. 2013;119(3):507-515. doi:10.1097/ALN.0b013e3182a10e26

10. Gu W-J, Hou B-L, Kwong JSW, et al. Association between intraoperative hypotension and 30-day mortality, major adverse cardiac events, and acute kidney injury after non-cardiac surgery: a meta-analysis of cohort studies. Int J Cardiol. 2018;258:68-73. doi:10.1016/j.ijcard.2018.01.137

11. O'Neal JB, Shaw AD, Billings FT. Acute kidney injury following cardiac surgery: current understanding and future directions. Crit Care. 2016;20(1):1-9. doi:10.1186/s13054-016-1352-z

12. Fleisher LA, Fleischmann KE, Auerbach AD, et al. 2014 ACC/AHA guideline on perioperative cardiovascular evaluation and management of patients undergoing noncardiac surgery: a report of the American college of cardiology/American heart association task force on practice guidelines. J Am Coll Cardiol. 2014;64(22):e77e137. doi:10.1016/j.jacc.2014.07.944 
13. An R, Pang Q-Y, Liu H-L. Association of intra-operative hypotension with acute kidney injury, myocardial injury and mortality in non-cardiac surgery: a meta-analysis. Int J Clin Pract. 2019;73(10): e13394. doi:10.1111/ijcp.13394

14. Barash PG, Cullen BF, Stoelting RK, Cahalan M, Stock MC. Clinical Anesthesia. 6th ed. Philadelphia: Lippincott Williams and Wilkins; 2009:230.

15. Harari S. The changing face of the European respiratory review. Eur Respir Rev. 2018;27:150. doi:10.1183/16000617.0102-2018

16. Sharafkhaneh A, Spiegelman AM, Main K, Tavakoli-Tabasi S, Lan C, Musher D. Mortality in patients admitted for concurrent COPD exacerbation and pneumonia. COPD. 2017;14(1):23-29. doi:10.1080/15412555.2016.1220513

17. López-Campos JL, Tan W, Soriano JB. Global burden of COPD. Respirology. 2016;21(1):14-23. doi:10.1111/resp.12660

18. Miskovic A, Lumb AB. Postoperative pulmonary complications. Br J Anaesth. 2017;118(3):317-334. doi:10.1093/bja/aex002

19. Cha Y-H, Ha Y-C, Park H-J, et al. Relationship of chronic obstructive pulmonary disease severity with early and late mortality in elderly patients with hip fracture. Injury. 2019;50(9):1529-1533. doi:10.10 16/j.injury.2019.05.021
20. Marseu K, Slinger P. Peri-operative pulmonary dysfunction and protection. Anaesthesia. 2016;71:46-50. doi:10.1111/anae.13311

21. Chu -C-C, Weng S-F, Chen K-T, et al. Propensity score-matched comparison of postoperative adverse outcomes between geriatric patients given a general or a neuraxial anesthetic for hip surgery: a Population-Based Study. Anesthesiology. 2015;123(1):136-147. doi:10.1097/ALN.0000000000000695

22. Hausman MSJ, Jewell ES, Engoren M. Regional versus general anesthesia in surgical patients with chronic obstructive pulmonary disease: does avoiding general anesthesia reduce the risk of postoperative complications? Anesth Analg. 2015;120(6):1405-1412. doi:10.1213/ANE.0000000000000574

23. van Lier F, van der Geest PJ, Hoeks SE, et al. Epidural analgesia is associated with improved health outcomes of surgical patients with chronic obstructive pulmonary disease. Anesthesiology. 2011;115 (2):315-321. doi:10.1097/ALN.0b013e318224cc5c
Clinical Interventions in Aging

\section{Publish your work in this journal}

Clinical Interventions in Aging is an international, peer-reviewed journal focusing on evidence-based reports on the value or lack thereof of treatments intended to prevent or delay the onset of maladaptive correlates of aging in human beings. This journal is indexed on PubMed Central, MedLine, CAS, Scopus and the Elsevier
Dovepress

Bibliographic databases. The manuscript management system is completely online and includes a very quick and fair peer-review system, which is all easy to use. Visit http://www.dovepress.com/ testimonials.php to read real quotes from published authors. 